\title{
Comparative Evaluation of Coolant Mixing Experiments at the ROCOM, Vattenfall, and Gidropress Test Facilities
}

\author{
S. Kliem, B. Hemström, Y. Bezrukov, T. Höhne, and U. Rohde
}

Received 25 May 2007; Accepted 25 October 2007

Recommended by Regina Galetti

Coolant mixing is an important mitigative mechanism against reactivity accidents caused by local boron dilution. Experiments on coolant mixing were carried out at three different test facilities representing three different reactor types. These are the ROCOM test facility modelling a German KONVOI-type reactor, the Vattenfall test facility being a model of a Westinghouse three-loop PWR, and the Gidropress test facility modelling a VVER-1000 PWR. The scenario of the start-up of the first main coolant pump was investigated in all three facilities. The experiments were accompanied by velocity measurements in the downcomer for the same scenario in the ROCOM and the Vattenfall test facilities. A similar flow structure was found in these measurements in both cases. A maximum of the velocity is measured at the opposite side in regard to the position of the loop with the starting-up pump whilst a recirculation area was found just below this inlet nozzle in both facilities. The analysis of the slug mixing experiments showed also comparable flow behaviour. In accordance with the velocity measurements, the first part of the deboration is also found on the opposite side. In this region, the maximum deboration is measured in all three cases. These maximum values are in the same order of magnitude for nearly identical initial slug volumes.

Copyright ( 2007 S. Kliem et al. This is an open access article distributed under the Creative Commons Attribution License, which permits unrestricted use, distribution, and reproduction in any medium, provided the original work is properly cited.

\section{INTRODUCTION}

The quantitative assessment of the mixing of coolant with different properties inside the reactor coolant system during normal operation or hypothetical accidents is in the focus of experimental and numerical investigations, for several years now. These different properties might be different temperatures, different densities, and/or different concentrations of additives. The most relevant additive to the primary coolant in pressurized water reactors (PWRs) is boron acid used for the control of reactivity. In some cases, dependent on the scenario of the transient, both temperature and boron acid concentration might be different in a certain part of the coolant; in some cases, density differences due to temperature gradients can be neglected with respect to mixing.

Boron dilution generally refers to a transient or accident, where the boron acid content in at least some parts of the primary circuit fluid is smaller than the nominal value. A slug of lower-borated water can be formed in the primary circuit by various mechanisms. Causes might be injection of coolant with less boron content from interfacing systems (external boron dilution) or separation of the borated reactor coolant into highly concentrated and diluted fractions (inherent boron dilution). The mixing of these lower borated slugs with water of higher boron concentration is a very im- portant mechanism in order to avoid serious reactivity accidents in local boron dilution transients. This is therefore one of the most important nuclear safety-related issues of coolant mixing. Significant advantage in boron dilution transient analysis can be achieved, if realistic mixing data are used $[1,2]$.

The EC-funded project FLOMIX-R (FIKS-CT-200100197) aimed at the experimental and numerical investigation of the coolant mixing phenomena relevant for safety analysis, particularly in steam line break and boron dilution scenarios, as well as of interest for the economical operation and the structural integrity. A significant part of the work in this project was the experimental investigation of the mixing of coolant with different properties on the way from the cold leg through the downcomer and lower plenum to the core inlet in a systematic way. The obtained data should help in the clarification of the mixing mechanisms and should form a data base for the validation of computational fluid dynamics (CFD) codes.

The literature reports that a number of test facilities have been used to study coolant mixing, where each facility considers the different geometrical aspects of various reactor types. In case of [3-5], the facilities were solely designed to study the inadvertent pump start-up, that is, they examined activation of a circulation pump only in one of 
the loops; the other loops remained passive. Other test facilities were dedicated to the mixing of ECC water injected into the cold leg of a PWR [6-8] or directly into the reactor pressure vessel [9]. Only the ROCOM test facility operated at Forschungszentrum Dresden-Rossendorf (FZD)(Dresden, Germany) and the $2 \times 4$ thermal-hydraulic loop facility (scaled down model of a Babcock\&Wilcox PWR) operated at the University of Maryland [10,11] have been used for experimental investigations of both types of the above-mentioned mixing scenarios.

Experiments on slug mixing have been performed in the frame of the project at two of the above-mentioned test facilities. These are the Rossendorf test facility ROCOM, modelling a German KONVOI-type reactor, and the Vattenfall test facility, being a model of the Westinghouse three-loop PWR in Ringhals. The corresponding accident scenario is the start-up of the first main coolant pump (MCP) after formation of a slug of lower borated water during the refluxcondenser mode phase of a small break loss of coolant accident (LOCA). The matrices for the experiments were elaborated on the basis of the key phenomena, being responsible for the coolant mixing during pump start-up. Slug mixing tests have also been performed at the VVER-1000 facility of EDO Gidropress to meet the specifics of this reactor type. All three test facilities model the corresponding original reactor in scale of $1: 5$.

The present paper is dedicated to the comparative analysis of the slug mixing experiments at these three facilities. Furthermore, velocity measurements carried out by means of laser Doppler anemometry (LDA) at the ROCOM and the Vattenfall test facilities are compared.

\section{DESCRIPTION OF THE TEST FACILITIES}

\subsection{The ROCOM test facility}

The ROCOM test facility models the primary circuit of a German KONVOI-type reactor in a linear scale of $1: 5$ $[12,13]$. The reactor pressure vessel was manufactured from acrylic glass and forms the main part of the test facility (Figure 1). The geometrical similarity between the model and the original reactor is fully respected within the region in between the bends in the cold legs, which are the closest to the reactor inlet and to the core entrance. The geometry of the inlet nozzles with their diffuser segments and the curvature radius of the inner wall at the junction with the pressure vessel were modelled in detail. Similarity is also taken into account for the core support plate with the orifices for the coolant. The original KONVOI reactor has a perforated sieve drum (flow skirt below the core barrel), which is also placed in the lower plenum of the vessel in the ROCOM test facility (Figure 2).

ROCOM is a four-loop test facility with individually controllable pumps in each loop, which enables the possibility of performing tests over a wide range of flow conditions, from natural circulation to nominal flow rates and this includes the use of ramped flow rate changes to simulate normal or natural operation conditions (Figure 3).

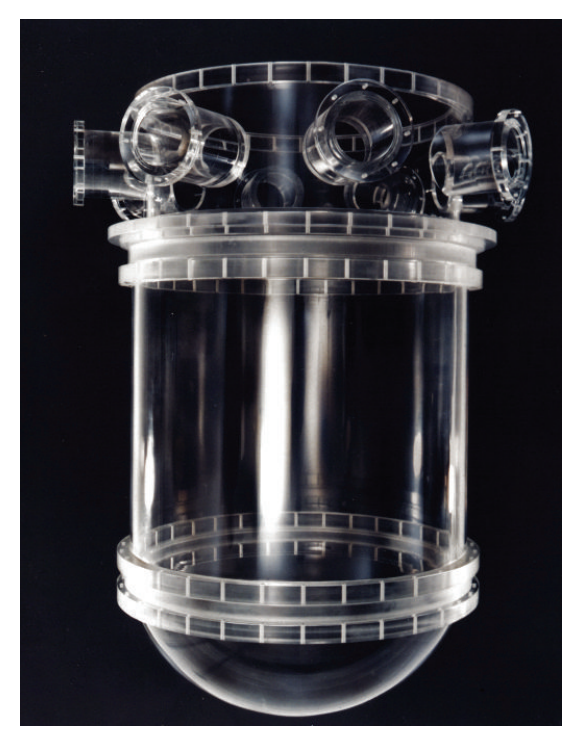

Figure 1: Vessel of the ROCOM test facility.

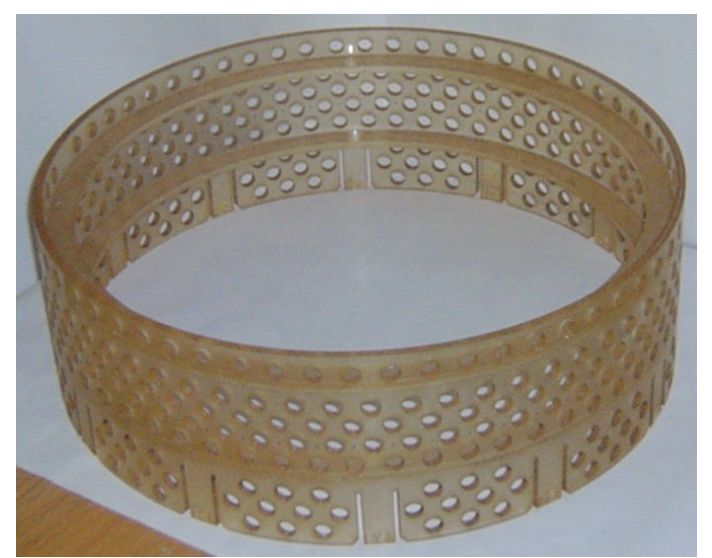

FIGURE 2: Sieve drum in the lower plenum of the ROCOM test facility.

The facility is operated with water at room temperature and ambient pressure. Since the coolant mixing is mainly based on turbulent dispersion, it is possible to use a tracer substance to model differences of either boron concentration or coolant temperature. In case of ROCOM, the coolant in the disturbed loop was labelled by injecting a sodium chloride solution into the main coolant flow upstream of the affected reactor inlet nozzle. For this purpose, loop 1 of ROCOM was equipped with a mixing device, which distributes the tracer solution uniformly across the cross section of the main circulation pipe. Start and stop of the injection process was controlled by pneumatic valves. The concentration distribution of the tracer within the reactor model is measured by electrical conductivity sensors, which allow a high resolution determination of the transient tracer concentration in space and time (Prasser, 1998). Four such sensors were installed in the reactor pressure vessel model in the experiments described here with altogether about 1000 single measurement positions and a measuring frequency of up to 




Figure 3: Schematic of the ROCOM test facility.

$200 \mathrm{~Hz}$. The location of the sensors in the model is shown in Figure 4.

The measured conductivity values are transformed into a mixing scalar $\Theta_{x, y, z}(t)$. It is calculated by relating the local instantaneous conductivity $\sigma_{x, y, z}(t)$ to the amplitude of the conductivity change in the inlet nozzle of the disturbed loop,

$$
\Theta_{x, y, z}(t)=\frac{\sigma_{x, y, z}(t)-\sigma_{0}}{\sigma_{1}-\sigma_{0}},
$$

where $\Theta$ represents the contribution of the coolant from the disturbed loop to the mixture at the given position $x, y, z$. The upper reference value $\sigma_{1}$ in (1) is the conductivity in the injected slug. The lower reference value $\sigma_{0}$ is the initial conductivity of the water in the test facility before the tracer is injected.

The transparent material for the pressure vessel allows the measurement of velocity profiles in the downcomer by laser Doppler anemometry.

\subsection{The Vattenfall test facility}

The Vattenfall mixing test facility is a 1 : 5 scale model of a 3-loop Westinghouse PWR [14, 15]. The lower plenum and the lower $2 / 3$ of the downcomer are made from acrylic glass. A general view of the facility is shown in Figure 5. Two idle loops are included in the model. The model is run with a maximum flow rate of $127 \mathrm{l} / \mathrm{s}$ and at temperatures between 20 and $50^{\circ} \mathrm{C}$. Components that can be important for mixing have been modelled, for example thermal shields, inlet pipe diffusers, structures in lower plenum (Figure 6), core support plates, and core. The determination of the relative boron concentration is based on salt water tracering and conductivity measurement too. Conductivity is measured at 181 measure- ment positions close to the inlet to the core. A sampling frequency of $60 \mathrm{~Hz}$ has been used.

The slug is injected into an empty section of the cold leg pipe that has been isolated from the rest of the pipe. The slug is released by quickly opening the two valves that encompass the slug. Flow through the model is then slowly (during around 40 seconds) increased to the maximum flow rate. The increased flow rate is achieved by opening a motor gate-valve upstream of the slug. In order to minimise buoyancy effects, ethanol is added to the salt water to lower the density of the salt water to that of tap water. The density difference is lower than $1 \mathrm{~kg} / \mathrm{m}^{3}$ after this adjustment.

In addition to the slug mixing experiments, the velocity profile in the downcomer can be measured by laser Doppler anemometry like in the case of the ROCOM test facility.

\subsection{The Gidropress test facility}

The test facility of EDO "Gidropress" [5] is a metal model of the Russian VVER-1000 reactor in a scale of $1: 5$. One loop with a loop seal and reactor coolant pump simulator is modelled. The other three loops are made short circuit, and only the pressure loss of them is simulated. The core model has 151 fuel assembly simulators, which have the same pressure loss as the regular fuel assembly. Boron concentration change is modelled by a change in temperature (the deborated water slug is simulated by colder water). About 100 thermocouples are placed in the lower part of the downcomer and at the core inlet to study the mixing of flows.

The schematic of the test facility is presented in Figure 7, whilst Figure 8 shows the reactor model and Figure 9 the elliptical plate located in the lower plenum of the test facility together with the supporting tubes. All reactor model components were made from stainless steel. 


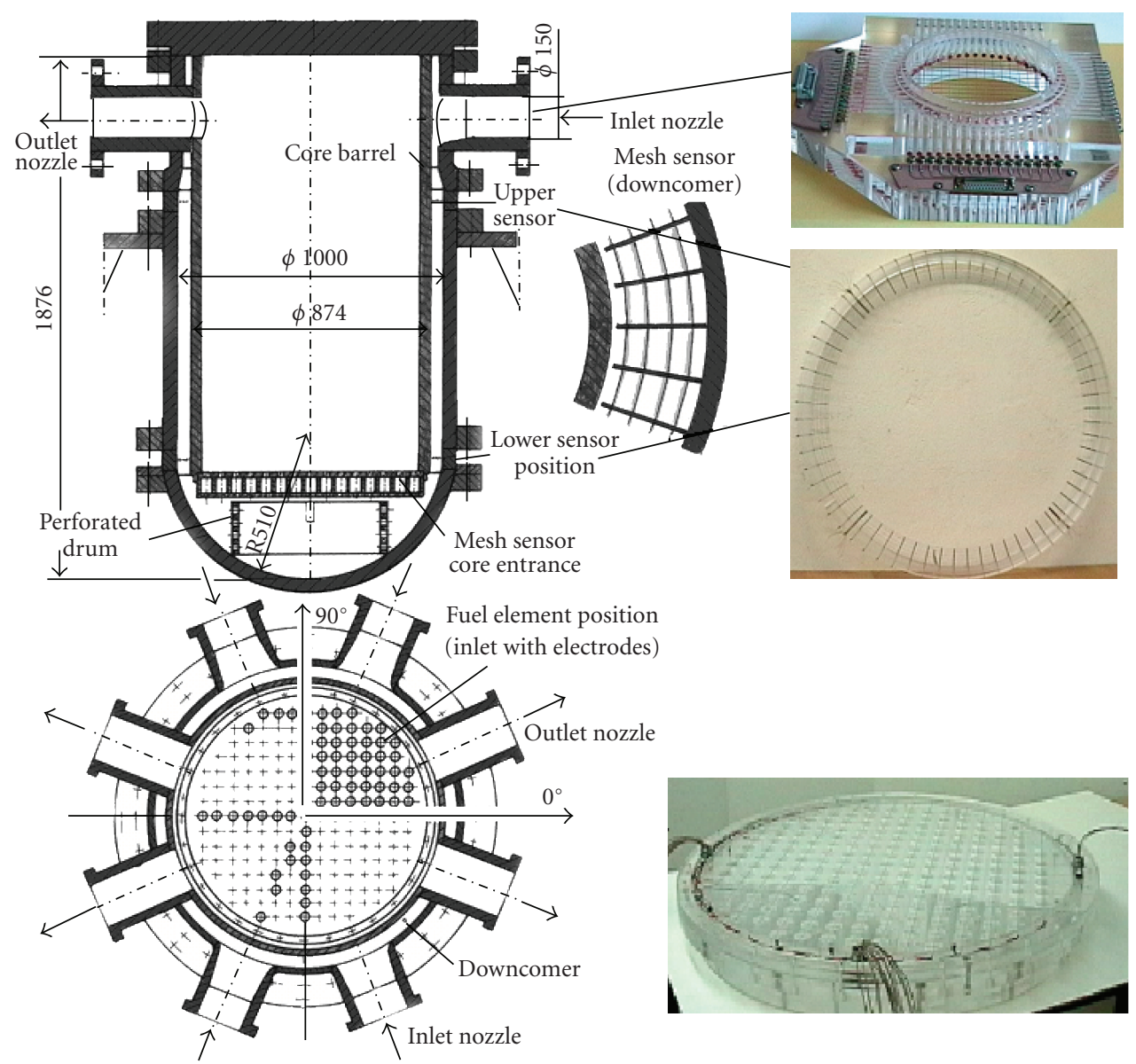

FIGURE 4: Schematic of the ROCOM model of the vessel with positions and photos of the wire mesh sensors.

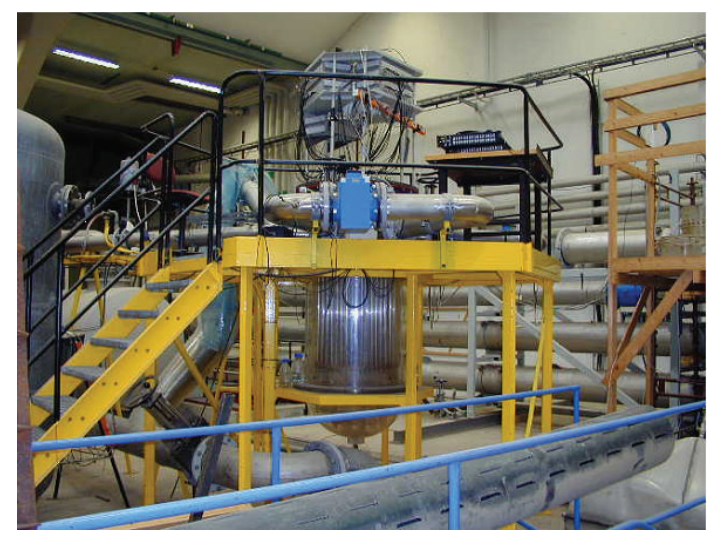

FIGURE 5: General view of the Vattenfall test facility.

\section{VELOCITY MEASUREMENTS}

\subsection{ROCOM}

Velocity measurements were conducted for the basic pump start-up scenario. The coolant was at rest in the whole test facility in the initial state. The flow rate in loop 1 is increased to the nominal value (according to the geometrical scale)

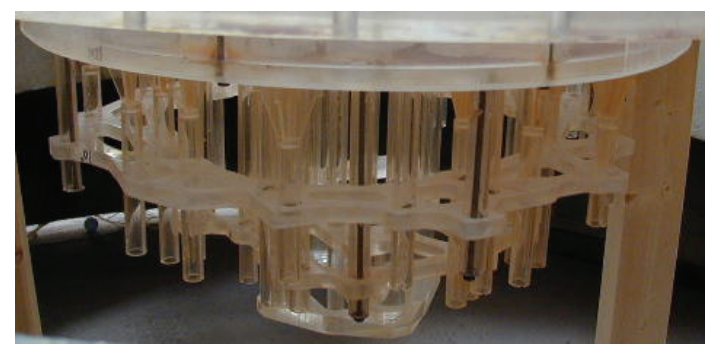

FIGURE 6: Structures in the lower plenum of the Vattenfall test facility.

within the nominal start-up time of 14 seconds. This value is held constant until $t=30$ seconds after which the pump is stopped and the flow come to rest for a period of $30 \mathrm{sec}-$ onds. It should be mentioned, that a reverse flow establishes in each of the three passive loops during the start-up of the circulation at a level of about $5 \%$ of the nominal value.

The whole process was repeated five times, all occurring bursts in the LDA system were recorded. The vertical and the horizontal components of the velocity were measured not simultaneously at 16 circumferential positions at the outlet from the downcomer of the test facility. The measurement 


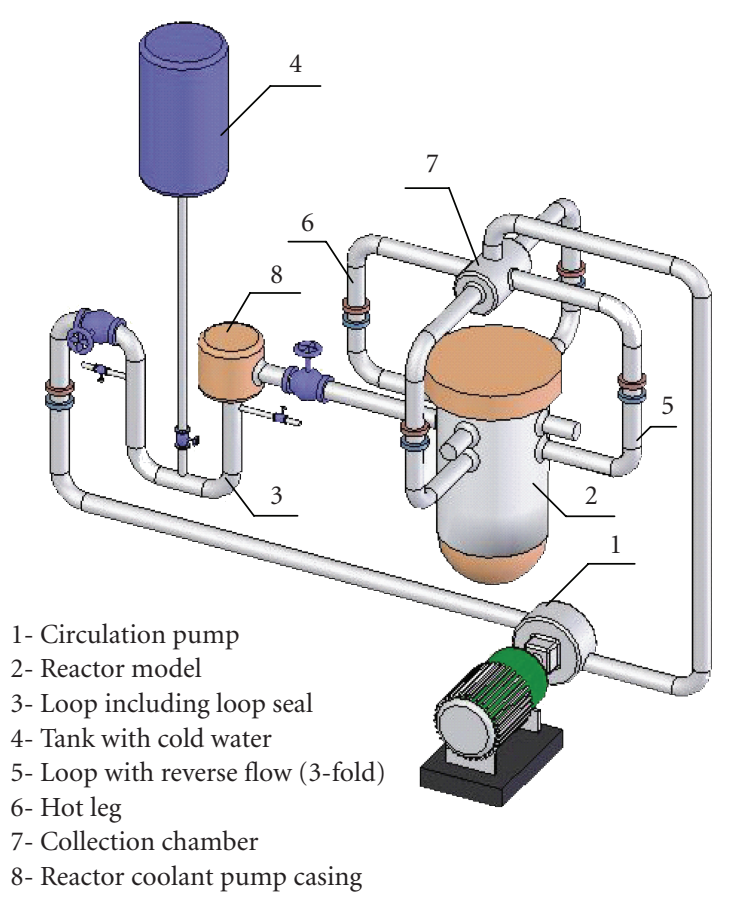

FIGURE 7: Schematic of the "Gidropress" test facility.

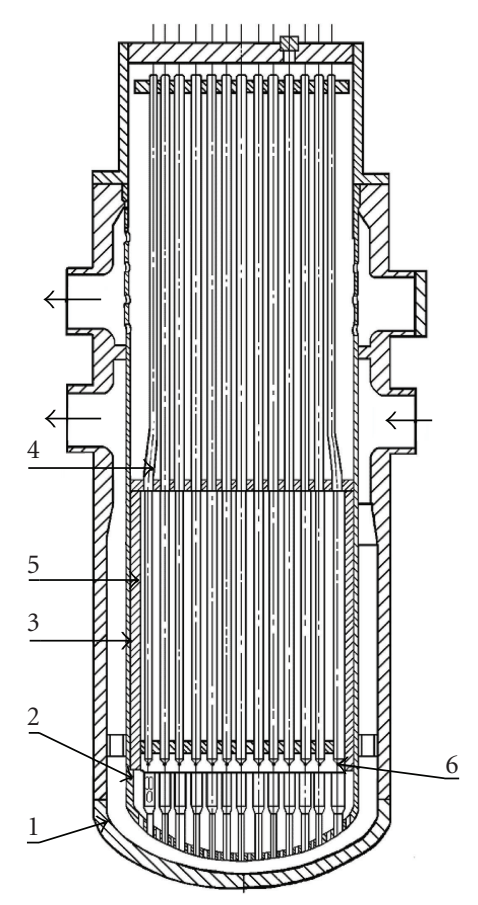

1- Vessel

2- Core barrel bottom

3- Core barrel

4- Guide tubes

5- Core baffle

6- Thermocouples

FIGURE 8: Reactor model of the "Gidropress" test facility.

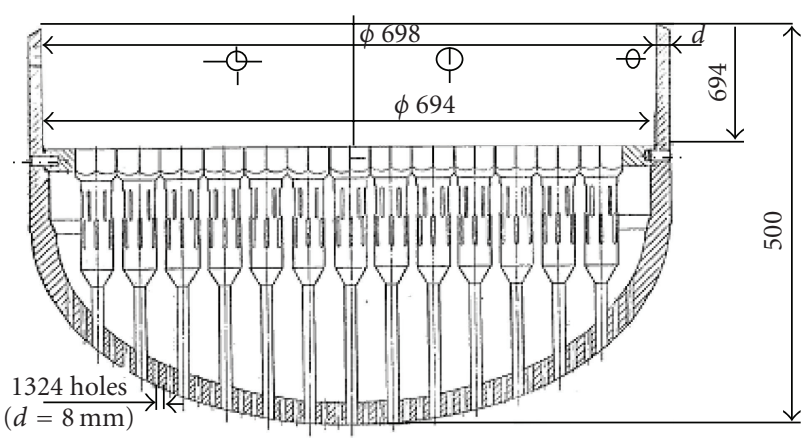

FIGURE 9: Lower plenum elliptical plate with supporting tubes of the "Gidropress" test facility.

position was always at the midpoint between the outer and inner downcomer walls.

In a recent paper by Cartland Glover et al. [16], the velocity measurements of this and a second start-up scenario were analysed in detail in regard to the development and the dissipation of the transient flow. This included a Fourier analysis and the derivation of the turbulent kinetic energy from the measurements.

Here, the main focus is put on the vertical velocity measurements in the downcomer in order to compare the results with those obtained at the Vattenfall test facility.

In the ROCOM measurements, the number of measured values (registered bursts) is not constant over time. In the parts of the transient with low velocity, sometimes no data were recorded over several seconds. Nevertheless, the obtained data allow drawing conclusions about the flow behaviour during the start-up process.

Figure 10 shows the time evolution of the velocity in the starting-up loop and the LDA measurements for different angle positions at the outlet of the downcomer. The inlet nozzle of the starting-up loop is located at an angle of $22.5^{\circ}$.

At $t=0$ second, the pump is switched on. The measurements show an increase of the loop velocity starting about 3 seconds later. This delay is a combination of the inertia of the coolant and the measurement system for the loop flow rate. After this, the velocity increases more or less linearly until the final value.

The middle diagram of Figure 10 shows all measurement values for two angle positions left and right of the loop with the starting circulation, in the lower diagram the values measured at two positions at the opposite side of the downcomer are shown. The velocity increases more or less uniformly at all four positions within the first 8 seconds (negative values of the velocity indicate downwards-directed flow, positive upwards directed). That means that the fluid is brought into motion as a whole by the starting-up pump. Large-scale vortexes start to develop in the next seconds, as was found by Cartland Glover et al. [16]. In the consequence, the downwards velocity on the opposite side increases further, whilst the flow direction changes in the region below the inlet nozzle of the loop with the starting-up pump. Here, a recirculation area is established. The third phase of the transients begins, when the flow rate in the loop has reached its final 


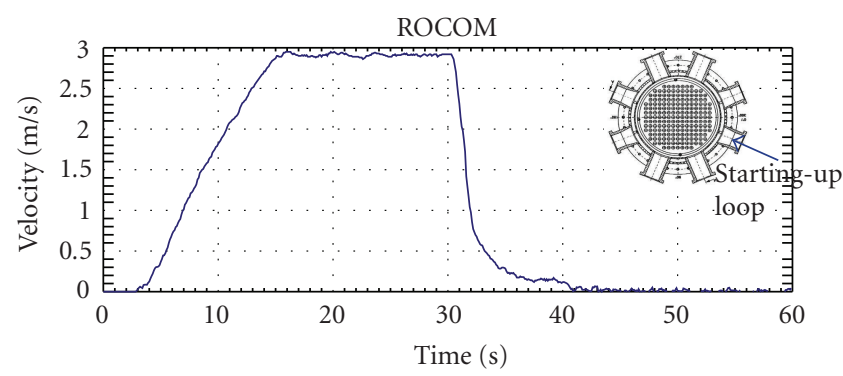

(a)

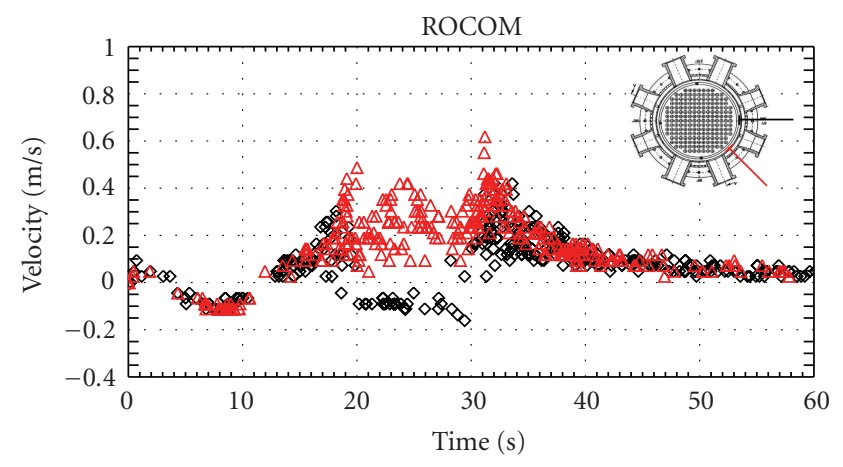

$-0^{\circ}$

$-45^{\circ}$

(b)

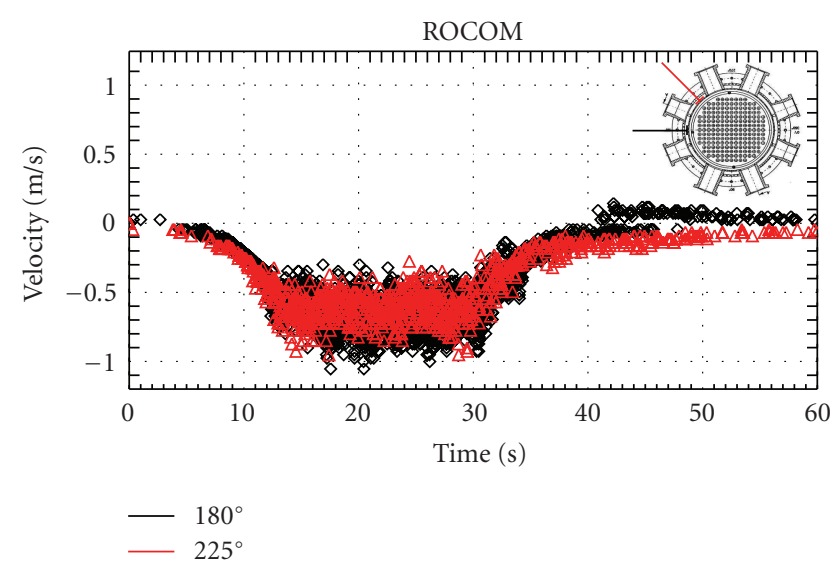

(c)

Figure 10: Time evolution of the velocity in the starting-up loop and the LDA measurements for different angle positions at the outlet of the downcomer in the ROCOM test facility.

value. Turbulent fluctuations around a nearly constant average value are observed now at each measurement position. Fluctuations and average value are nearly identical at the angle positions on the opposite side of the downcomer. More time is needed to establish stable flow conditions in the region below the affected inlet nozzle. Here, the flow structure undergoes a further change. The resulting flow field shows positive (upwards-directed) values at a position left to the starting up loop and negative (downwards-directed) values on the other side. The amplitudes at both positions are considerably lower than those on the opposite side.

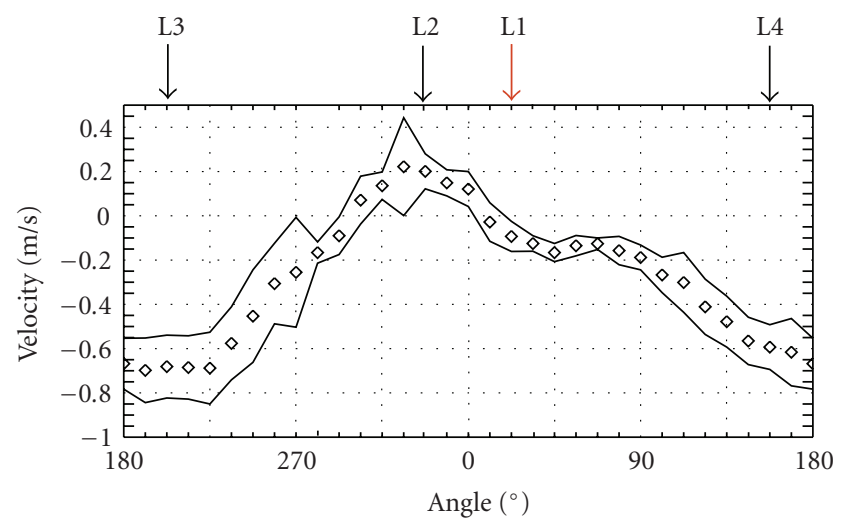

FIGURE 11: Vertical velocity profile including standard deviation at the outlet of the downcomer of the ROCOM test facility during oneloop operation under steady-state conditions.

The velocity profile under steady state conditions corresponding to the final state of the pump start-up scenario is shown in Figure 11. This profile was measured in a special measurement series. Stationary flow conditions were established in the facility and measurements at 32 circumferential positions were carried out. On basis of the obtained data, the standard deviation was calculated for each measurement position. This data is also included in Figure 11. This measured under stationary conditions profile confirms the observation from the transient measurements. The maximum of the downwards-directed velocity is found on the opposite side of the downcomer directly below the inlet nozzle of loop 3. This maximum is not concentrated on one measurement position but has a width of about $45^{\circ}$. A stagnation point is found directly below the inlet nozzle of the loop with the starting-up pump. The maximum of the upwardsdirected velocity is measured below the neighbouring inlet nozzle (loop 2). It is the centre point of a region with positive velocity values (upwards-directed flow), which has an extension of about $60^{\circ}$. The overall velocity profile has a clear asymmetry in regard to the position of the starting-up loop. This asymmetry is caused by the different distances of the neighbouring inlet nozzles. One should further consider that the lead-through of two outlet nozzles is located between the inlet nozzles of loop 1 and 4, which also disturb the flow field in the downcomer.

The flow behaviour after the switch off of the pump at $t=$ 30 seconds is analysed in detail by Cartland Glover et al. [16] and will not be discussed here.

\subsection{Vattenfall}

LDA measurements were also performed for the basic pump start-up scenario at the Vattenfall test facility. In this experiment, the flow rate increases from zero to the final value within about 17 seconds. The final value in the loop is $6.85 \mathrm{~m} / \mathrm{s}$ (Figure 12, upper diagram). This value is 2.48 times higher than the full scale maximum velocity ( $1 / 5$ of the velocity in the reference plant); as the test was run with an increased flow rate in order to increase the Reynolds number 




(a)

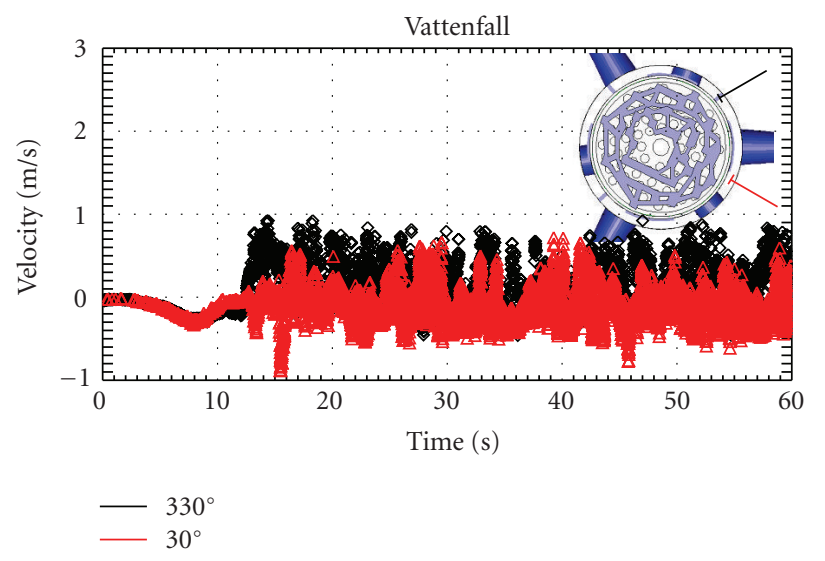

(b)



$-210^{\circ}$

$-150^{\circ}$

(c)

FIGURE 12: Time evolution of the velocity in the starting-up loop and the LDA measurements for different angle positions at the outlet of the downcomer in the Vattenfall test facility.

and thereby to minimize the Reynolds number scaling effects. The ramp length was adjusted by the same factor in order to preserve the Strouhal number. Thus, the ramp length at the original plant is 2.48 times longer. For details about the scaling considerations the reader is referred to [17].

In the two passive loops, a reverse flow of about $10 \%$ of the nominal value is established. Vertical and tangential components of the velocity were measured simultaneously at six angle positions around the downcomer. These measurements were performed at two axial positions and up to four positions over the width of the downcomer. The whole set of measured data is documented in [14]. Each measurement is repeated five times. The whole measurement time in each case was 90 seconds. The switching off of the pump was not included into the measurements. As in the case of the ROCOM measurements, all bursts of the LDA systems are stored. From the whole set of available data, the transient data measured at the outlet of the downcomer at four different circumferential positions are used here. In each case, the radial measurement position is in the middle of the downcomer.

Figure 12 shows the time evolution of the loop velocity and the LDA data for two positions left and right of the starting-up loop and for two positions on the opposite side of the downcomer. The positions were selected in such a way that a comparison with the ROCOM data is possible. The inlet nozzle of the starting-up loop in the Vattenfall test facility is located at an angle of $0^{\circ}$.

The LDA data at all four angle positions until $t=7 \mathrm{sec}-$ onds indicate the same flow behaviour as in the ROCOM case. The water column is accelerated as a whole by the starting-up pump. After this initial phase, the velocity increases further at the two positions on the opposite side of the downcomer. A plateau value is reached shortly after that time, from which the loop flow rate remains unchanged. The measured velocity fluctuates around the constant average value at the plateau in the same manner as in the RO$\mathrm{COM}$ measurements. The differences of the plateau levels are considerably higher than in the ROCOM measurements.

At the two positions left and right from the starting-up loop (angle positions $30^{\circ}$ and $330^{\circ}$ ), the same qualitative behaviour as in the ROCOM case is observed. Starting from $t$ $=7$ seconds, the flow reverses and after a transition period of nearly 10 seconds a new quasistationary state is established. Right from the affected inlet nozzle, the averaged velocity is directed upwards, left from this nozzle downwards, the absolute values of the downwards-directed data are slightly lower. It is important to note that the change of the flow pattern occurs in the same way as in ROCOM.

Again, similar to the ROCOM measurements, fluctuations are to be seen in the Vattenfall data also at these positions.

Figure 13 shows the steady-state velocity profile for the quasistationary flow field with one working pump. As in the ROCOM measurements, there is a recirculation area below the inlet nozzle of the loop with the working pump. Although the number of measurement positions is limited, one could argue for the existence of a symmetry in relation to the measurement position, where the maximum upwards-directed value was found $\left(-30^{\circ}\right)$. Contrary to the ROCOM test facility, the inlet nozzles and the lead-through for the outlet nozzles are equally (symmetrically) distributed over the circumference of the downcomer. The only asymmetry introduced into the flow field comes from the bend in the loop with the working pump just before the entry into the vessel. The influence of this bend on the mixing has been discussed extensively in connection with the flow simulations 


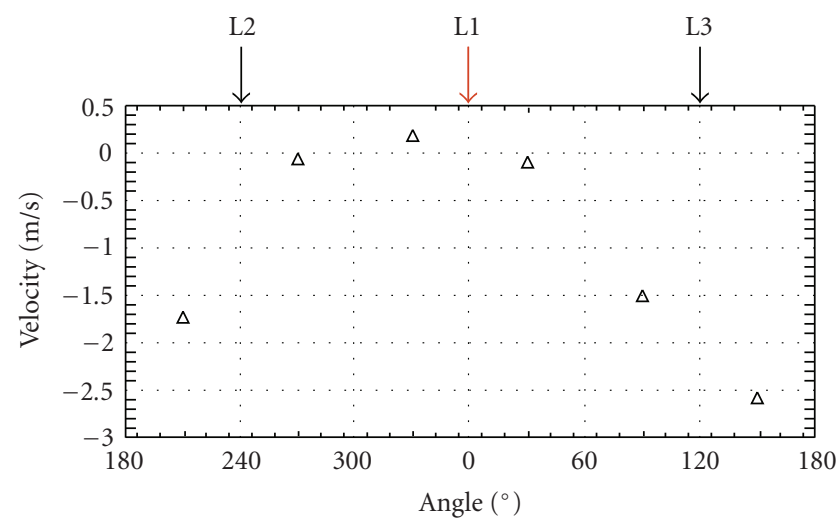

FIgURE 13: Vertical velocity profile at the outlet of the downcomer of the Vattenfall test facility during one-loop operation under steady-state conditions.

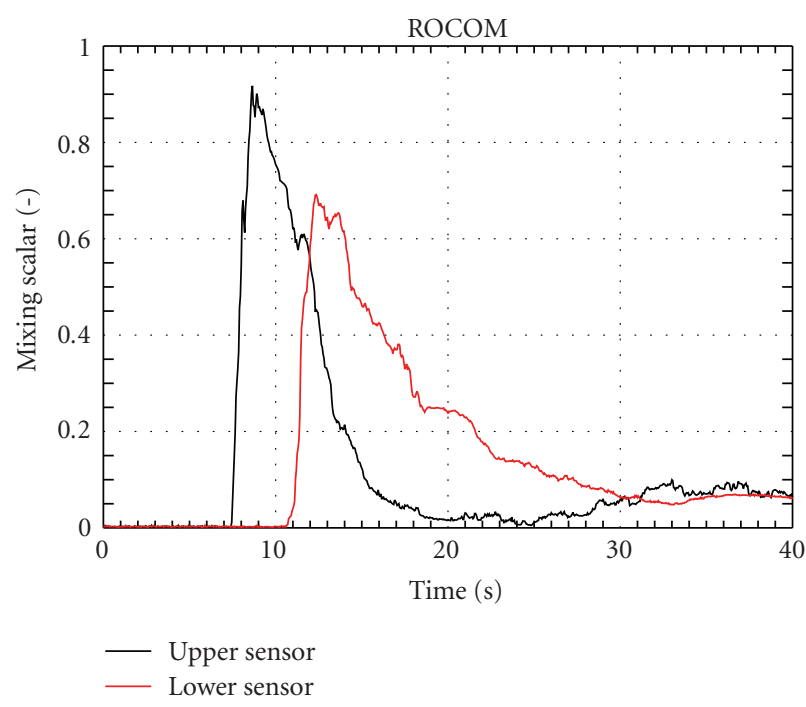

FIgURE 14: Maximum mixing scalar at the two downcomer sensors in the ROCOM experiment.

for the Vattenfall test facility [15]. It seems that this bend creates a significant tangential component of the velocity already in the loop, which results in a shift of the symmetry position of the vertical velocity field.

\section{SLUG MIXING EXPERIMENTS}

Slug mixing experiments from the three test facilities are compared in this section. All facilities are equipped with measurement devices in the core inlet plane. Information about the mixing in the downcomer is only available from the experiments at the ROCOM test facility.

Thus, in the first part of this section, the mixing in the downcomer is discussed on the basis of the ROCOM data. In the second part, the time-dependent results obtained at the core inlet in all three test facilities are discussed.

\subsection{Downcomer}

Besides the sensor in the core inlet plane, the ROCOM test facility is equipped with sensors in the downcomer. These sensors can provide more insight into the flow distribution and the physical mechanisms responsible for the obtained flow pattern at the core inlet. The sensors measure the tracer concentration in one radial plane. Two of such sensors were implemented into the upper and the lower part of the downcomer, respectively (see Figure 4 ). They represent $4 \times 64$ measuring positions, that is, the azimuthal distribution of the tracer concentration is measured at 64 angular positions with a pitch of $5.625^{\circ}$. Over the radius, there are 4 measuring positions with a radial pitch of $13 \mathrm{~mm}$.

During the transport, the slug mixes with the ambient coolant in the vessel and the perturbation reduces, as can be concluded from the decreasing maximum values reached at the two downcomer sensor positions (Figure 14).

Figure 15 shows the time evolution of the mixing scalar at the two sensors in the downcomer. Both sensors are shown in an unwrapped view, the position of the loop with the starting-up pump is marked by the red arrow. From the visualization, it is clear to see that the deborated coolant passes around the core barrel instead of flowing directly downstream. The slug hits the core barrel after the entry into the vessel and splits into two streaks. At the upper sensor, the tracer arrives still below the affected inlet nozzle. With growing time, the tracer spreads in the azimuthal direction. The two streaks flow downwards at the opposite side of the downcomer. Subsequently, at the lower sensor two maxima of the tracer at azimuthal positions on the back side of the downcomer are observed. It is important to note that the time scale in this figure is identical with this of the velocity measurements discussed above. At $t=11$ seconds, the first tracer reaches the measuring plane of the lower sensor. At this time, the flow field is in the final phase of the transition process to the quasistationary state. The main structure is already developed, so that the tracer distribution can be evaluated in comparison to the stationary velocity field (Figure 11). The two maxima of the tracer concentration are located in the region, where the maximum of the vertical velocity was measured. The region in between these two zones (below the inlet nozzle of the loop with the starting-up pump) is free of tracer for the next five seconds. Tracer is measured here starting from $t=16$ seconds. This tracer is transported into the measuring plane from below, as can be concluded from the velocity measurements. In this region, those measurements revealed a recirculation area.

The limited volume of the slug reveals the flow structure only for a certain time span of the pump start-up process. For the substantiation of the findings made above, an additional experiment was conducted with long-term tracer injection under stationary one-loop operation. Figure 16 shows the time evolution of the tracer in this special experiment. The shape of the tracer concentration at both sensors is similar to that of the first experiment. Nevertheless, some differences can be observed. The tracer distribution on the stream lines of the velocity field at the upper sensor is better to be seen in this experiment. The recirculation area revealed at the lower 




Figure 15: Time evolution of the mixing scalar at the two downcomer sensors in the ROCOM experiment (start-up of the main coolant pump).

sensor has a greater extension than in the start-up experiment. This can be also explained by the velocity measurements. The slug moved through the measuring plane at the opposite side from about $t=11$ seconds to $t=15$ seconds. The maximum of the velocity in the corresponding parts of the downcomer was not yet reached and the reconfiguration of the flow field below the inlet nozzle with the startingup loop was not yet finished. The stationary conditions in the additional experiment fully correspond to the conditions during the stationary velocity measurements. In this state, the differences between the velocity values on both sides of the downcomer are maximal. Further, the position of the free tracer sector corresponds fully to the upwards-directed part of the velocity profile. By tracer injection over such a long time interval, it is confirmed that the tracer directly below the inlet nozzle is transported into the measuring plane exclusively from below.

\subsection{Core inlet}

For the comparison of the time-dependent tracer distribution in the core inlet plane experiments have been selected from the three test facilities with close boundary conditions. Table 1 summarizes key parameters of the facilities and the selected experiments. It can be seen that the initial slug volume is nearly identical between the experiments. Figure 17 shows the flow rate in the loop with the

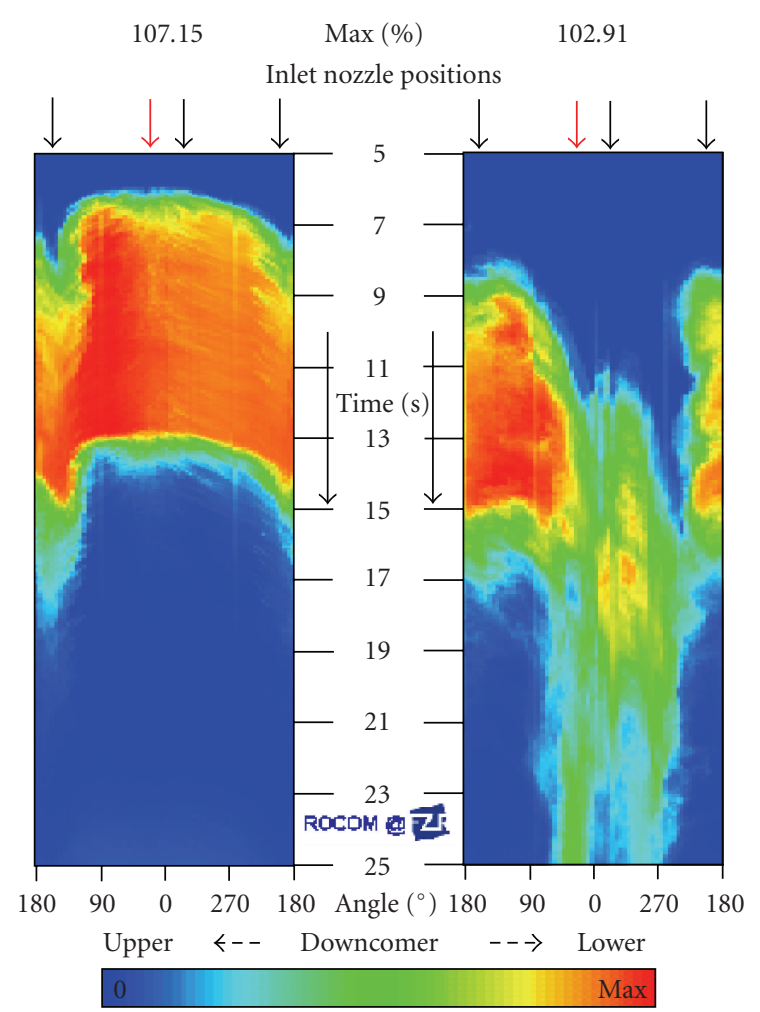

FIgUre 16: Time evolution of the mixing scalar at the two downcomer sensors in a stationary ROCOM experiment (one-loop operation).

starting-up pump at the different test facilities. The final rate is comparable in the different experiments, but the ramp of reaching this level differs in the single experiments. The flow paths in the facilities are also different. Due to these differences, the time of reaching the core inlet plane differs between the experiments. Figure 18 shows the time evolution of the average and the maximum mixing scalar in the three experiments. The data from the Vattenfall and the Gidropress experiments were transformed into the mixing scalar defined by (1). In this way, the results of the experiments can be better compared. As can be seen from Figure 18, the three slugs reach the core inlet at different times. A dimensionless time was introduced with the goal to bring the data into one time scale, which allows discussing the mixing processes independently on the absolute time. This dimensionless time is determined for each experiment individually. It is based on the time, which is needed to transport the perturbation through the measuring plan at the core inlet. Figure 19 shows the evolution of the mixing scalar in the experiments now in the dimensionless time.

The scaling applied here is comparable to a scaling with the preservation of the Strouhal number (Sr). The Strouhal number is the dimensionless number which characterises the nonstationarity of a flow. It describes the relation between the forces due to local acceleration (change of velocity at a given position) and the forces due to convective acceleration 
TABLE 1: Key parameters of the test facilities and the start-up experiments.

\begin{tabular}{|c|c|c|c|}
\hline & ROCOM & Vattenfall & Gidropress \\
\hline $\begin{array}{l}\text { Reference } \\
\text { reactor }\end{array}$ & German KONVOI PWR (four loops) & Westinghouse PWR (three loops) & VVER-1000 PWR (four loops) \\
\hline Scale & $1: 5$ & $1: 5$ & $1: 5$ \\
\hline $\begin{array}{l}\text { Cold leg } \\
\text { cross } \\
\text { section }\left[\mathrm{m}^{2}\right]\end{array}$ & 0.01767 & 0.01767 & 0.02956 \\
\hline $\begin{array}{l}\text { Downcomer } \\
\text { cross } \\
\text { section }\left[\mathrm{m}^{2}\right]\end{array}$ & 0.1854 & 0.1136 & 0.1290 \\
\hline $\begin{array}{l}\text { Downcomer } \\
\text { width }[\mathrm{m}]\end{array}$ & 0.063 & 0.050 & 0.053 \\
\hline Reverse flow & $3 * 5 \%$ & $2 * 10 \%$ & $3 * 0 \%$ \\
\hline $\begin{array}{l}\text { Final loop } \\
\text { flow rate } \\
{\left[\mathrm{m}^{3} / \mathrm{h}\right]} \\
\end{array}$ & 185 & 173 & 175 \\
\hline $\begin{array}{l}\text { Cold leg } \\
\text { Reynolds } \\
\text { number at } \\
\text { final flow } \\
\text { rate }[-]\end{array}$ & $4.35^{*} 10^{5}$ & $5.62 * 10^{5}$ & $7.75^{*} 10^{5}$ \\
\hline $\begin{array}{l}\text { Ramp } \\
\text { length [s] }\end{array}$ & 14 & 40 & 7 \\
\hline $\begin{array}{l}\text { Downcomer } \\
\text { flow rate } \\
{\left[\mathrm{m}^{3} / \mathrm{h}\right]}\end{array}$ & 157.3 & 188.4 & 175.0 \\
\hline $\begin{array}{l}\text { Slug volume } \\
{[1]}\end{array}$ & 64 & 64 & 74 \\
\hline
\end{tabular}

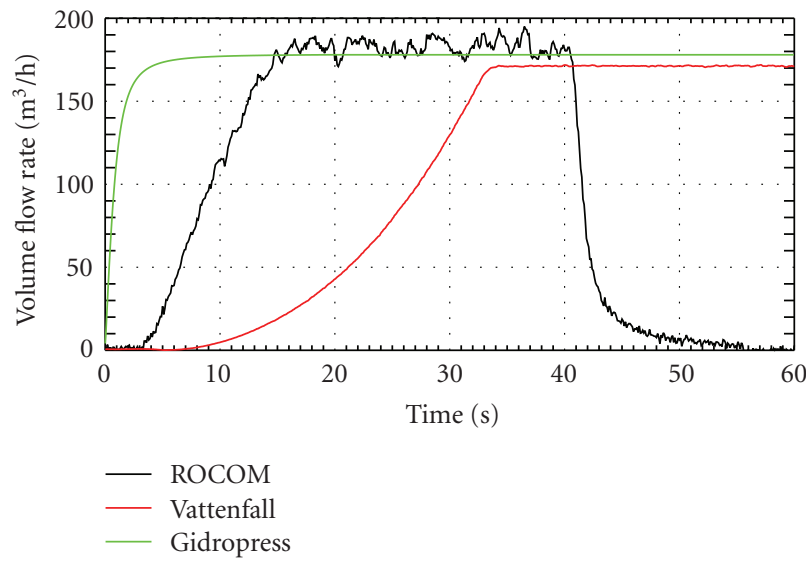

FIGURE 17: Flow rate in the starting-up loop in the experiments at the three test facilities.

(change of velocity due to change of position). The Strouhal number is defined as

$$
\mathrm{Sr}=\frac{L}{w \cdot \tau},
$$

where $L$ is the characteristic length, $w$ the characteristic velocity, and $\tau$ the characteristic time.

The height of the mixing scalars does not change in both types of scaling described above.

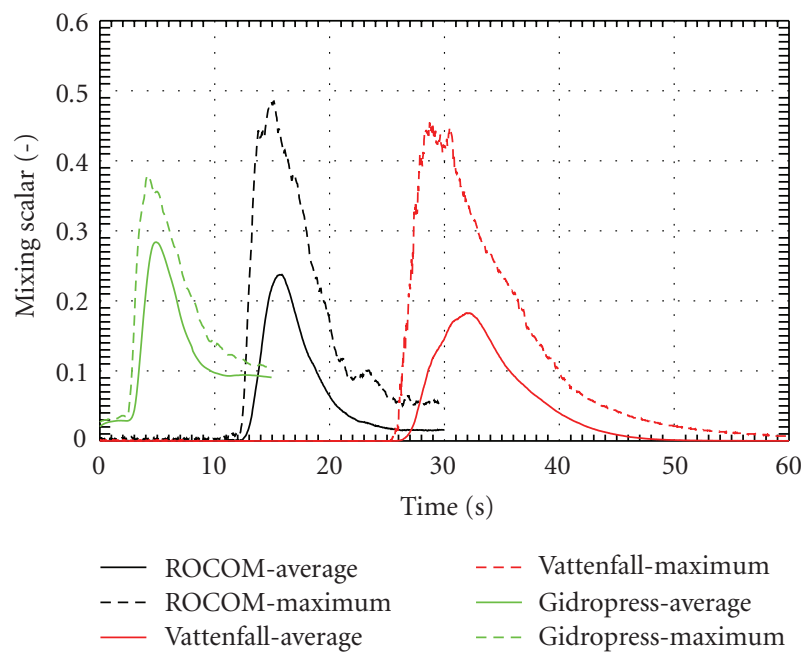

FIGURE 18: Time course of the average and the maximum mixing scalar in the different experiments.

The time curves of the average mixing scalar are nearly identical after the scaling.

Figures 20, 21, 22, and 23 show the snapshots of the core inlet distribution of the mixing scalar in all three experiments. The positions of the active and the passive cold legs 


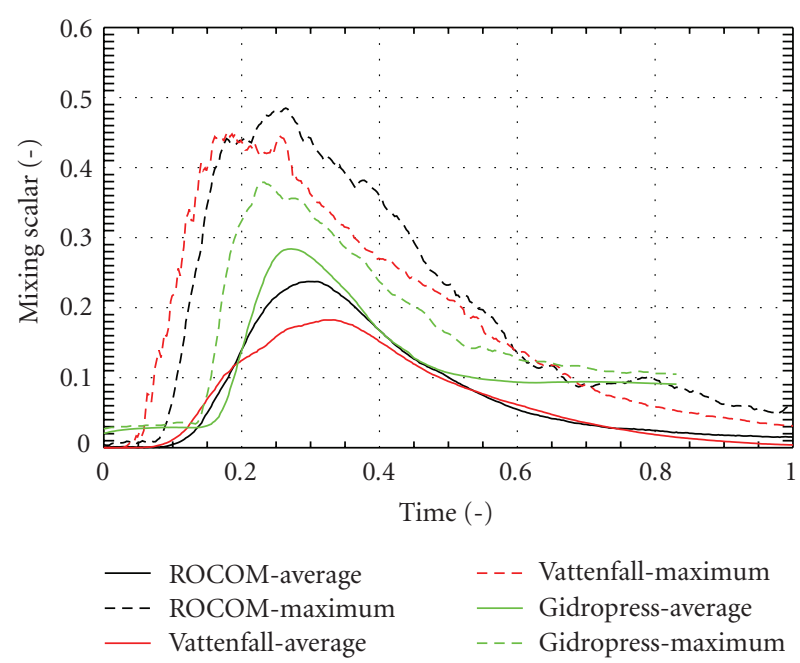

FIGURE 19: Average and maximum mixing scalar in the different experiments independent of dimensionless time.

are also shown. Although the time scales were brought in accordance, the perturbation reaches the measuring plane at the same time only in the ROCOM and the Vattenfall experiments; it is slightly delayed in the Gidropress experiment. This delay is connected with the fast increase of the flow rate in the Gidropress experiment, what makes the scaling difficult. A true Strouhal scaling, what is not applicable in this case, would eliminate this difference. This was shown for RO$\mathrm{COM}$ experiments with different ramps and flow rates, for example, in [18].

In the ROCOM experiment, first tracer appears at two positions on the opposite side of the core inlet plane in regard to the position of the loop with the starting-up pump. These positions are identical with the two maxima in the measuring plane of the lower downcomer sensor. (Already this comparison underlines that the main processes responsible for the mixing take place in the downcomer.)

At the same time, the first tracer appears also in the core inlet plane of the Vattenfall test facility at two positions located in the opposite half of the core inlet. The positions are nearly symmetrical in relation to the inlet nozzle of the loop with the starting-up pump. The amount of tracer is slightly higher at the position on the left side of this loop. The equal distribution of the three inlet nozzles facilitates the formation of a symmetrical flow field as was already stated in the analysis of the velocity profile (Figure 13). The remaining asymmetry is the result of the bend in the loop; see Figure 13.

In the ROCOM case, the symmetry line is shifted from the position of the active inlet nozzle to the right side. This shifting is a result of the velocity profile at the outlet of the downcomer (Figure 11) with its maximum around the angle position of $180^{\circ}$.

In the Gidropress experiment, the first part of the deboration is registered at two positions (one nearby the inlet nozzle with the starting-up pump, one on the opposite side) in the outer part of the core inlet plane. It is followed by a part of different shape in the central part of the measuring plane just below the inlet nozzle. It can be concluded that the initial slug is splitted into three streaks. Two of them move around the core barrel like in the other two facilities and one goes directly below the nozzle downwards.

The next snapshots (from $t=0.200$ to $t=0.300$ ) show that in all three cases, the shape of the perturbation changes only slightly. The mixing scalar increases at the positions established once. The global maxima are measured in this phase in all three cases. In the regions between the initial maxima, the perturbation reaches only lower values. The third phase of the slug moving through the core inlet plane is dominated by a unification of the perturbation zones. It starts in the Gidropress experiment. In the ROCOM experiment this process is accompanied by a shift of the perturbation from the opposite side to the side below the active inlet nozzle $(t=0.300$ to $t=$ 0.600). This fully corresponds to the observations in the downcomer. From the Vattenfall snapshots, it can be concluded that the region below the inlet nozzle with the starting-up pump is only covered by a small amount of the perturbation. A moving like in the ROCOM experiment cannot be observed. The highest degree of mixing takes place in the Gidropress experiment in this phase, where nearly no structures in the distribution of the perturbation can be observed in the snapshots starting from $t=$ 0.400 .

As far as in this last phase, only the tails of the slugs are involved, the perturbation does not reach such high values as in the early phase of the transient.

It was found in the experiments at all three test facilities that the time behaviour of the resulting mixing scalar at identical positions in the pressure vessel differs in each single realization of an experiment with identical boundary conditions. Fluctuations of the flow field in the reactor pressure vessel are the reason for these deviations between single realizations of one experiment. These fluctuations are due to the turbulent nature of the flow, and therefore they appear by chance to a certain degree. Thus, the experiments are repeated five or more times. The results of these single realizations were averaged. This was done to damp the statistical fluctuations as mentioned above. It is possible to use the data of the single realizations to carry out an uncertainty analysis of the obtained results. This was done for the ROCOM experiment according to the following procedure.

In the first step, the minimum error amount $\mathrm{FS}_{\min , \Theta}$ for each local value of the mixing scalar at each time point is calculated according to (3), using the averaged values and the $n$ single realizations:

$$
\begin{aligned}
& \mathrm{FS}_{\min , \Theta}(x, y, z, t) \\
& \quad=\sum_{k=1}^{n}\left(\theta_{\mathrm{ROCOM}, k}(x, y, z, t)-\bar{\theta}_{\mathrm{ROCOM}}(x, y, z, t)\right)^{2} .
\end{aligned}
$$




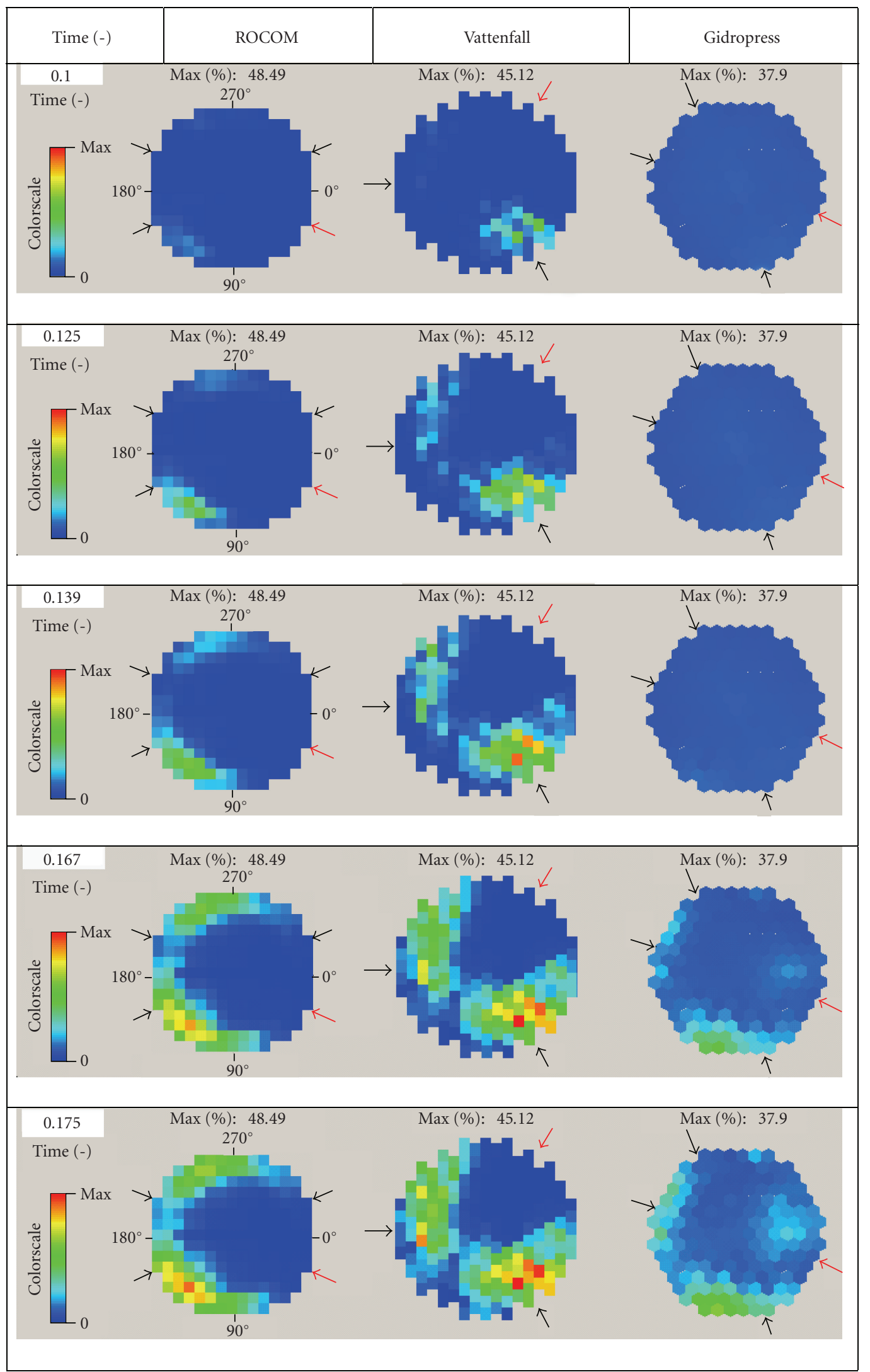

FIGURE 20: Time sequences of the mixing scalar in the core inlet plane of all three test facilities. 


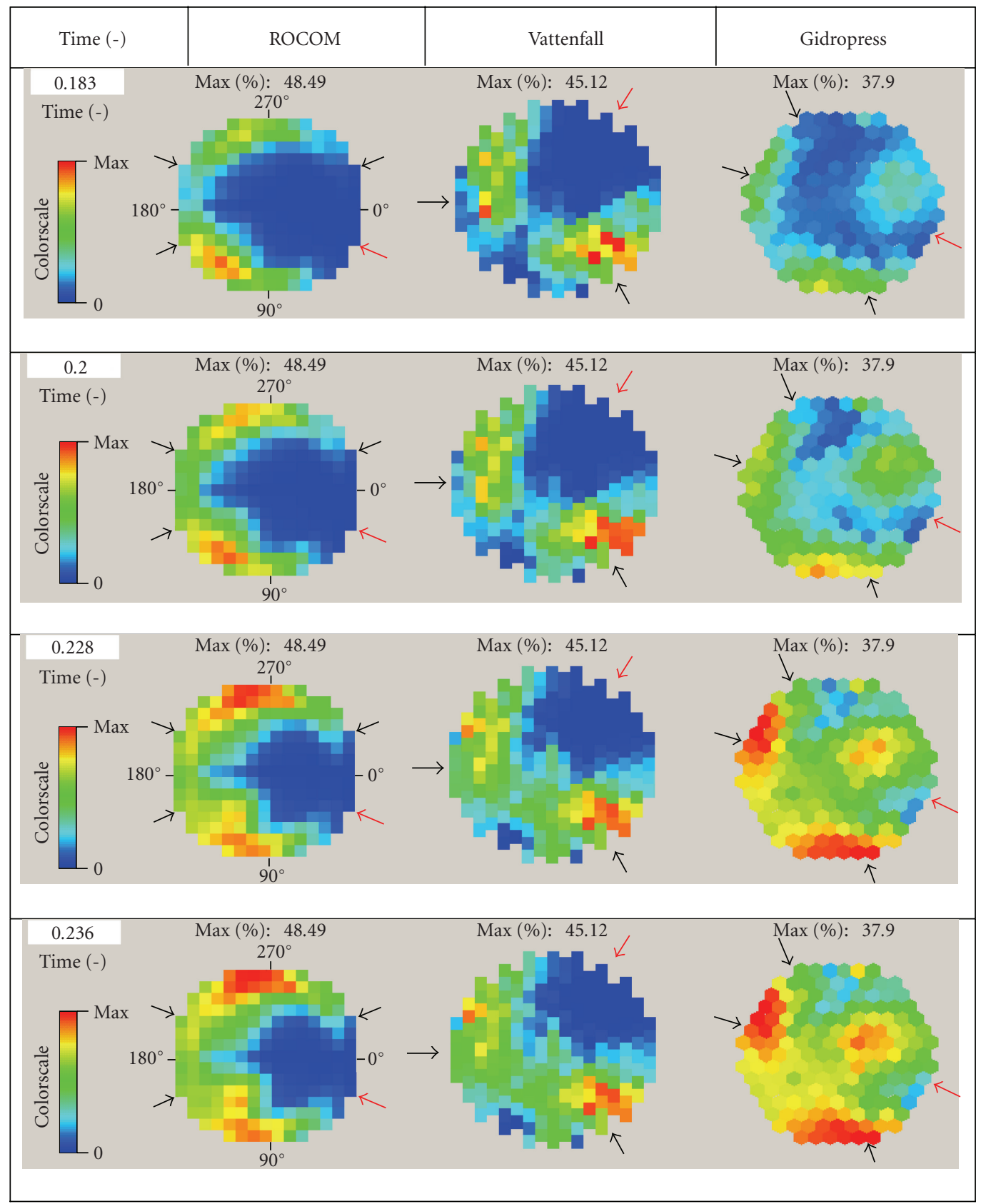

FIGURE 21: Time sequences of the mixing scalar in the core inlet plane of all three test facilities.

The standard deviation is calculated according to

$$
s_{\Theta}(x, y, z, t)=\sqrt{\frac{\mathrm{FS}_{\min , \Theta}(x, y, z, t)}{n-1}} .
$$

In the last step, the confidence intervals can be calculated using

$$
u_{z, \Theta}(x, y, z, t)= \pm t_{P} \cdot \frac{s_{\Theta}(x, y, z, t)}{\sqrt{n}} .
$$

This confidence interval characterizes the interval around the average value in which the measured value can be found with a given probability of the statistical confidence. Hereby, $t_{P}$ is the value of the Student's $t$-factor, which varies with the selected statistical confidence. Using (3) to (5), the time curves for the confidence intervals for $95.4 \%(2 \sigma)$ were calculated, whereby $\sigma$ is the square root of the variance of the distribution. Figure 24 shows the time curve of the maximum mixing scalar together with the $95.4 \%$-confidence interval. The confidence interval varies in time. This is due to the variation of the fluctuations during the investigated process.

The confidence interval for the Vattenfall experiments was assessed in a similar manner. A value of $6.5 \%$ (in absolute 

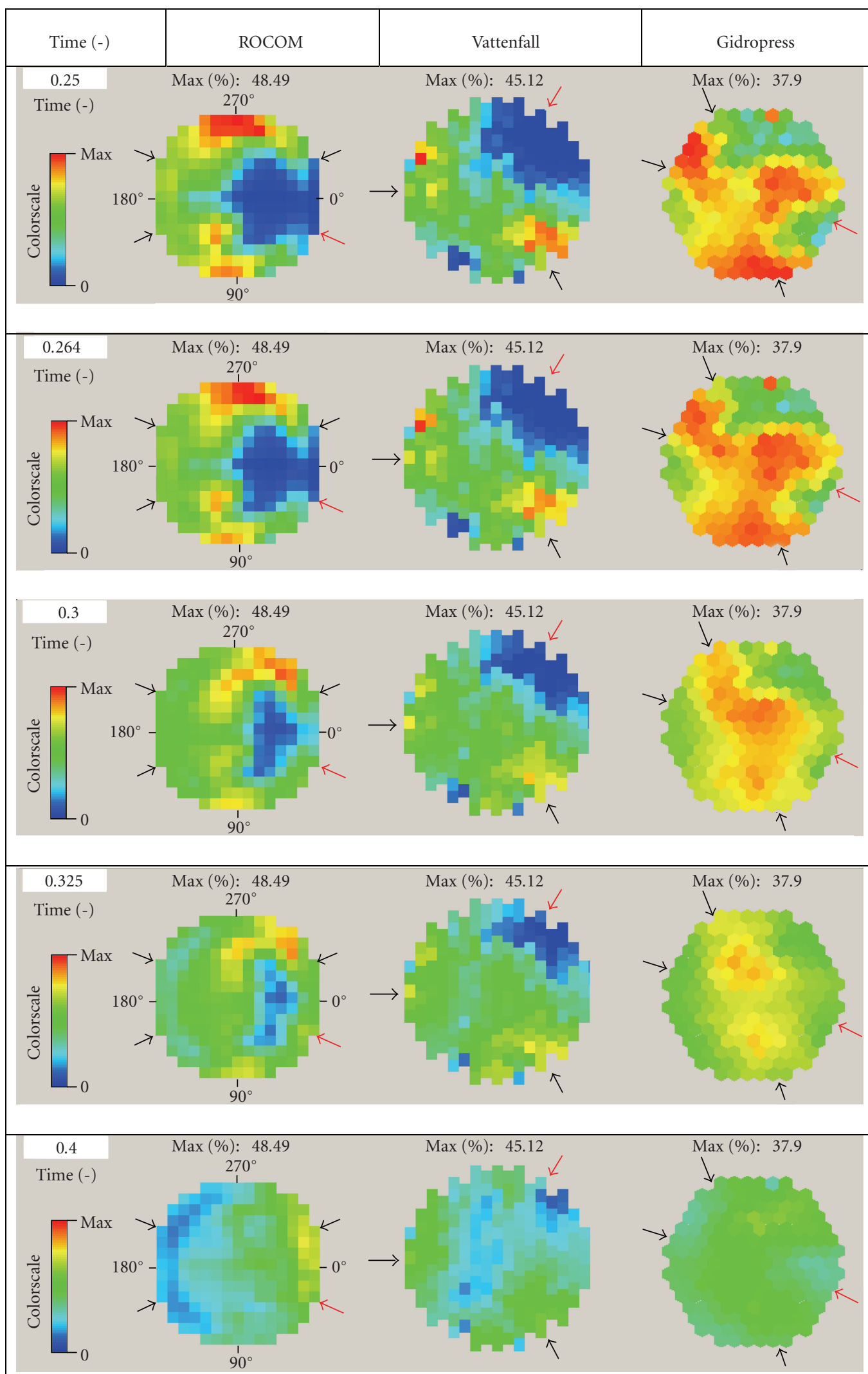

FIGURE 22: Time sequences of the mixing scalar in the core inlet plane of all three test facilities. 


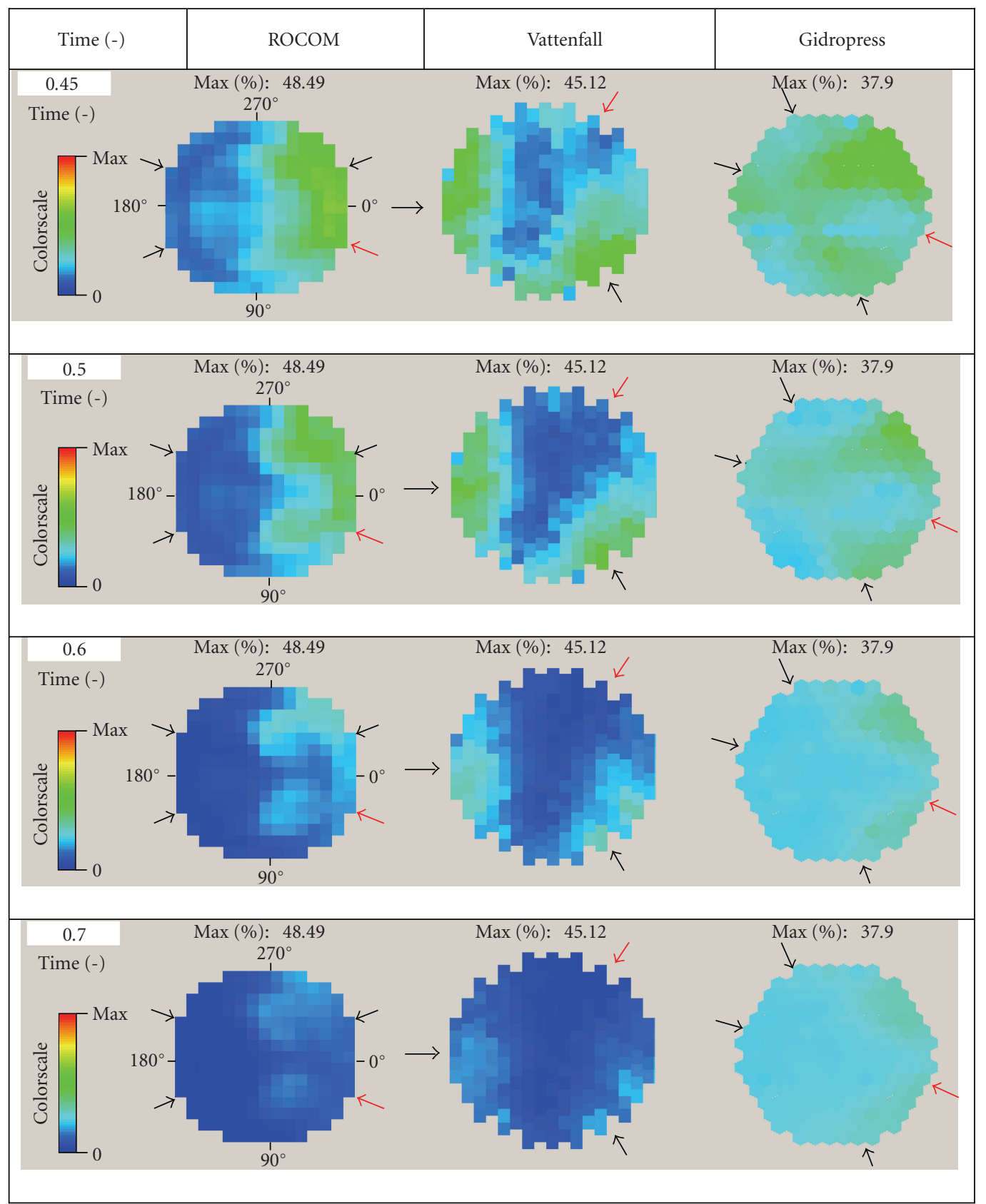

FIGURE 23: Time sequences of the mixing scalar in the core inlet plane of all three test facilities.

units) was determined for a typical measurement position during the start-up process of the first pump. The time curve of the maximum mixing scalar of the Vattenfall experiment together with the constant 95.4\%-confidence interval is added to Figure 24. Both confidence intervals are nearly identical, as can be concluded from Figure 24 .

\section{CONCLUSIONS}

The velocity measurements in the downcomer of the ROCOM and the Vattenfall test facilities revealed a complicated structure of the flow field during the start-up of the first main coolant pump. It was shown that the development of the flow field goes through three different phases in a similar manner in both test facilities. The findings of the velocity measurements are supported by the mixing data available for the downcomer from the ROCOM experiment. A maximum of the velocity is measured at the opposite side in regard to the position of the loop with the starting-up pump whilst a recirculation area was found just below this inlet nozzle in both facilities.

The initial perturbation undergoes a further attenuation during moving through the lower plenum as could be shown for the ROCOM experiment. The shape of the perturbation 


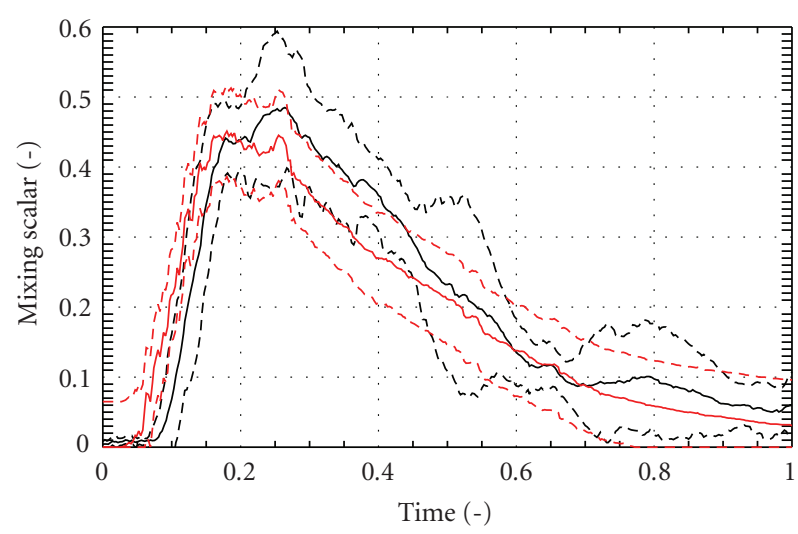

$\begin{array}{ll}- \text { ROCOM-maximum } & - \text { Vattenfall-maximum } \\ --- \text { ROCOM-confidence } & --- \text { Vattenfall-confidence }\end{array}$

Figure 24: Time evolution of the maximum mixing scalar in the core inlet plane together with the $95.4 \%$ confidence interval for the ROCOM and the Vattenfall experiments

does not change anymore. It corresponds mainly to the measured velocity profile in both cases and the downcomer mixing data in the ROCOM case. An important result of the experiments at all three test facilities is that the first part of the perturbation reaches the core inlet plane on the opposite side in regard to the position of the inlet nozzle of the loop with the starting-up pump. For comparable initial slug volumes, the maximum deboration is nearly identical in the Vattenfall and the ROCOM tests. The slightly higher value of the ROCOM experiments is still covered by the confidence interval. The Gidropress experiment shows a lower maximum value. This is probably connected with the lower plenum structures, which are much more complicated than in the other two reactor types. It is expected that the experiments carried out currently in the frame of an EC-TACIS project at the Gidropress test facility will provide more information on the mixing processes and on the influence of different boundary conditions.

\section{ACKNOWLEDGMENT}

The project in this paper was funded by EC under Contract FIKS-CT-2001-00197.

\section{REFERENCES}

[1] U. Grundmann and U. Rohde, "Investigations on a boron dilution accident for a VVER-440 type reactor by the help of the code DYN3D," in Proceedings of ANS Topical Meeting on Advances in Reactor Physics: Reactor Physics Faces the 21st Century, vol. 3, pp. 464-471, Knoxville, Tenn, USA, April 1994.

[2] S. Kliem, U. Rohde, and F.-P. Weiss, "Core response of a PWR to a slug of under-borated water," Nuclear Engineering and Design, vol. 230, no. 1-3, pp. 121-132, May 2004.

[3] D. Alvarez, O. Daubert, L. P. Janvier, and J. P. Schneider, “Three dimensional calculations and experimental investigations of the primary coolant flow in a 900 MW PWR vessel," in Proceedings of the 5th International Topical Meeting on Nuclear Reactor Thermal Hydraulics (NURETH-5 '92), vol. 2, pp. 586592, Salt Lake, Utah, USA, September 1992.

[4] F. Alavyoon, B. Hemström, N. G. Andersson, and R. I. Karlsson, "Experimental and computational approach to investigating rapid boron dilution transients in PWRs," in Proceedings of the CSNI Specialist Meeting on Boron Dilution Reactivity Transients, State College, Pa, USA, October 1995.

[5] O. I. Melikhov, V. I. Melikhov, S. E. Yakush, Y. Bezrukov, and S. A. Logvinov, "Analysis of boron dilution in VVER-1000 reactor," in Proceedings of the Annual Meeting on Nuclear Technology, pp. 117-120, Bonn, Germany, May 2001, INFORUM $\mathrm{GmbH}$.

[6] D. Häfner, et al., "HDR safety program-thermal mixing in the cold leg and downcomer of the HDR test rig," Report PHDR 91-89, FZ, Karlsruhe, Germany, 1990.

[7] H. Tuomisto, "Thermal-hydraulics of the Loviisa reactor pressure vessel overcooling transients, Imatran Voima Oy," Research Report IVO-A-01/87, 1987.

[8] R. J. Hertlein, K. Umminger, S. Kliem, H.-M. Prasser, T. Höhne, and F.-P. Weiss, "Experimental and numerical investigation of boron dilution transients in pressurized water reactors," Nuclear Technology, vol. 141, no. 1, pp. 88-107, 2003.

[9] C.-R. Choi, T.-S. Kwon, and C.-H. Song, "Numerical analysis and visualization experiment on behavior of borated water during MSLB with RCP running mode in an advanced reactor," Nuclear Engineering and Design, vol. 237, no. 7, pp. 778790, 2007.

[10] M. Gavrilas and K. Kiger, "ISP-43: rapid boron dilution transient experiment," Comparison Report, NEA/CSNI/R 22, 2000 .

[11] B. Woods, UM $2 \times 4$ loop experimental findings on the effect of inertial and buoyancy forces on annular flow mixing for rapid boron dilution transients, Ph.D. thesis, University of Maryland, College Park, Md, USA, 2001.

[12] H.-M. Prasser, G. Grunwald, T. Höhne, S. Kliem, U. Rohde, and F.-P. Weiss, "Coolant mixing in a pressurized water reactor: deboration transients, steam-line breaks, and emergency core cooling injection-experiments and analyses," $\mathrm{Nu}$ clear Technology, vol. 143, no. 1, pp. 37-56, 2003.

[13] T. Höhne, S. Kliem, and U. Bieder, "Modeling of a buoyancydriven flow experiment at the ROCOM test facility using the CFD codes CFX-5 and Trio_U," Nuclear Engineering and Design, vol. 236, no. 12, pp. 1309-1325, 2006.

[14] B. Hemström, "Data sets of the slug mixing experiments at the Vattenfall test facility," EU/FP5 FLOMIX-R report, FLOMIXR-D06, Vattenfall Utveckling AB, CDROM, 2004.

[15] B. Hemström, et al., "Validation of CFD codes based on mixing experiments (Final Report on WP4)," EU/FP5 FLOMIX$\mathrm{R}$ report, FLOMIX-R-D11, Vattenfall Utveckling (Sweden), 2005.

[16] G. M. Cartland Glover, T. Höhne, S. Kliem, U. Rohde, F.-P. Weiss, and H.-M. Prasser, "Hydrodynamic phenomena in the downcomer during flow rate transients in the primary circuit of a PWR," Nuclear Engineering and Design, vol. 237, no. 7, pp. 732-748, 2007.

[17] U. Rohde, S. Kliem, B. Hemström, T. Toppila, and Y. Bezrukov, "The European project FLOMIX-R: description of the slug mixing and buoyancy related experiments at the different test facilities," (Final report on WP 2), Report FZR430, Rossendorf, Dresden, Germany, 2005. 
[18] S. Kliem, T. Höhne, H.-M. Prasser, U. Rohde, and F.-P. Weiss, "Experimental investigation of coolant mixing in the RPV of a PWR during natural circulation conditions," in Proceedings of the 12th International Conference on Nuclear Engineering (ICONE-12 '04), vol. 3, pp. 711-720, 2004, (CD-ROM), paper 49424.

\section{AUTHOR CONTACT INFORMATION}

S. Kliem: Institute of Safety Research, Forschungszentrum Dresden-Rossendorf, P.O. Box 510119, 01314 Dresden, Germany; s.kliem@fzd.de

B. Hemström: Vattenfall Utveckling AB, 81426 Älvkarleby, Sweden; bengt.hemstrom@vattenfall.com

Y. Bezrukov: FSU EDO Gidropress, 21 Ordzhonikidze Street, Podolsk 142103, Russia; bezrukov@grpress.podolsk.ru

T. Höhne: Institute of Safety Research, Forschungszentrum Dresden-Rossendorf, P.O. Box 510119, 01314 Dresden, Germany; t.hoehne@fzd.de

U. Rohde: Institute of Safety Research, Forschungszentrum Dresden-Rossendorf, P.O. Box 510119, 01314 Dresden, Germany; u.rohde@fzd.de 

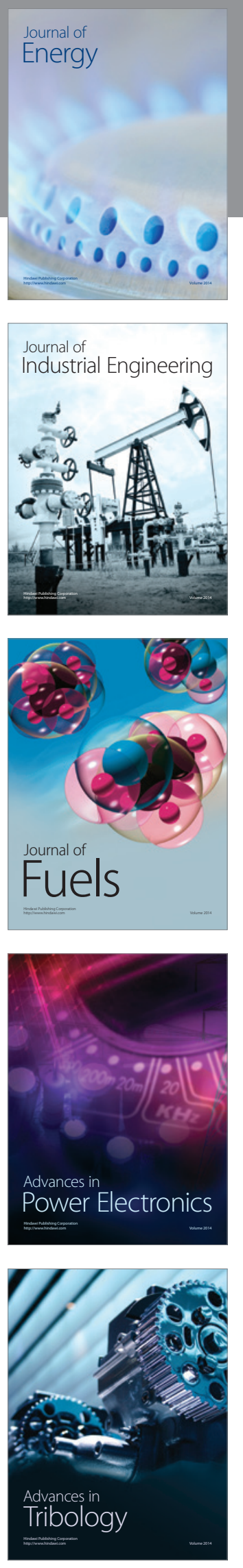


The Scientific World Journal



Submit your manuscripts at http://www.hindawi.com
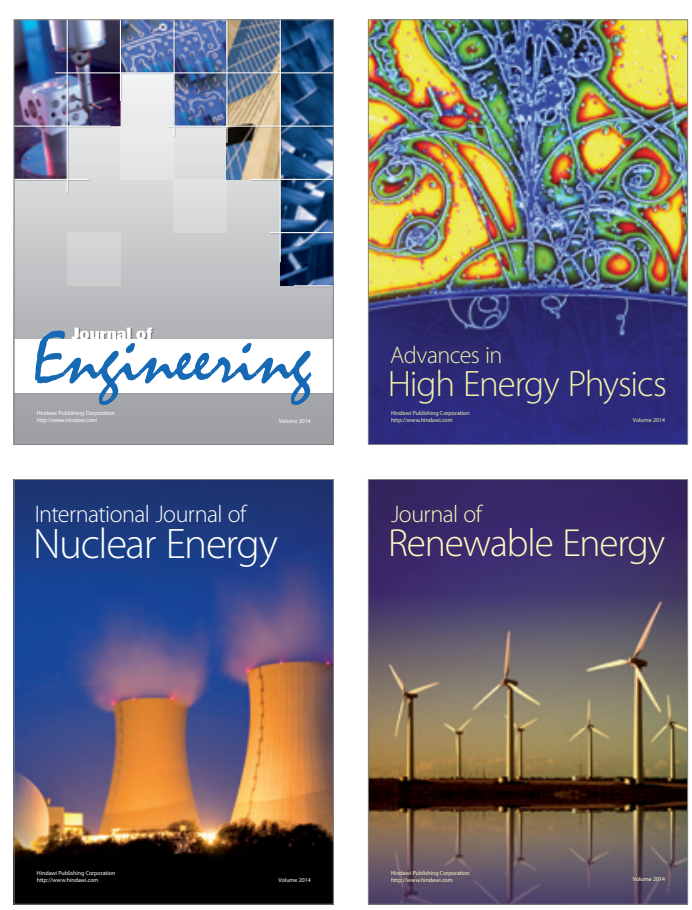

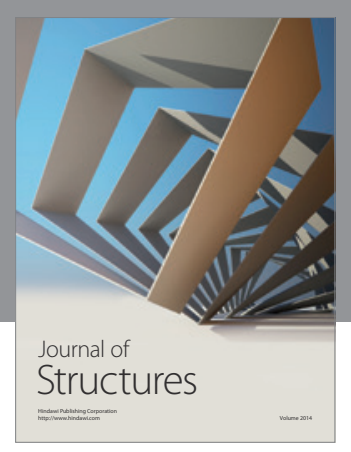

Rotating
Mechinery
